\title{
Research on English Translation Strategies for Chinese Cultural Classics
}

\author{
Zhihui Man \\ Teaching and Research Institute of Foreign Languages, Bohai University, Jinzhou, 121013, China \\ amandalove41@163.com
}

Keywords: Chinese cultural classics; English translation; theoretical basis; existing problems; translation strategies

\begin{abstract}
The English translation of Chinese cultural classics refers to a kind of language activities that Chinese cultural classics are translated into English, which are accurately and completely represent in English. In view of problems existing in the English translation of Chinese cultural classics, such as that the lack of planning ability, the disconnection between theory and practice, the lack of attention to ethnic minorities' books, the need to strengthen cooperation and exchange. Adopting functional equivalence, multiple systems and translation theories such as "faithfulness, expressiveness and elegance" to put forward Chinese cultural classics English translation strategies: integrate academic achievements of China and the west, take account of the theory and practice of translation; strengthen ethnic minorities' English translation, promote the Chinese culture to the world; facing the existence of cultural differences, using the principle of cultural equivalence; strengthen the organization work of classics translation, explore the unity and cooperation of various parties; construct the classics translation corpus system to solve the problems of pragmatic failure; strengthen disciplines construction, cultivate excellent translation talents troops.
\end{abstract}

\section{Introduction}

China is an ancient civilization country with a long history, Chinese culture is extensive and profound. In five thousand years of history, Chinese culture shows the strong adaptability and regeneration ability, which has the stability and sustainability, not only gives birth to the splendid and glorious history, but also promotes the development of surrounding countries that makes outstanding contributions to human civilization. However, there is a huge contrast between current China's foreign cultural transmission as well as the impact of Chinese culture on the world with Chinese culture connotation and brilliance. Works translation is an effective means of cultural communication. But both the quantity and quality of translated output works are difficult to compare with translated works, which leads to unequal culture exchange activities between China and other countries. Therefore, transcending cultural barriers, strengthening the external communication of the Chinese excellent culture, promoting the understanding and communication with the international community, which is conducive to establish a positive image of China, conducive to take an active position in international affairs for China, beneficial to create a good international environment for economic development, conducive to promote the world peace and development. How to overcome international culture obstacles and strengthen the external communication and exchange of the Chinese culture becomes a major proposition of the times.

Chinese culture classics which are preserved and handed down by Chinese characters are key carriers of Chinese culture, as well as the common spiritual wealth of all mankind. The English translation of Chinese culture classics refers to a kind of language activities that Chinese cultural classics are translated into English, accurately and completely represented in English. Classics English translation plays an important role in promoting Chinese culture and world cultural exchanges. Translation is no longer a borderline subject, but a comprehensive strong discipline with extensive concern, which draws research results of related disciplines and also becomes the important condition for the continuous improvement of related disciplines. In recent years, the theory of translation has developed, but it has not formed a scientific theory system, especially in 
the field of English translation. This paper solves strategy problems of improving the level of culture classics English translation based on rich classics translation theories, from the perspective of classics translators and disseminator, which services for carrying forward the Chinese culture and promoting Chinese cultural classics to the world.

\section{Theoretical Basis on English Translation for Chinese Cultural Classics}

Translation has a strong theorization and rich practical connotation. The translation theory is namely the theory involved in the process of translation, some theories can be directly described and acquired through training, while some theories can only stay at the theoretical level. The translation theory and practice are dialectical relations, translation theories are produced in the translation practice, which guide practice in turn, the practice also riches translation theories. On the whole, translation theory researches lag behind the achievements obtained in the field of translation practice. Without practice there will be no translation theories, if there are no translation theories as guidance, the translation practice will take a detour. Therefore, it is necessary to attach importance to translation theories as well as strengthening the translation practice. Learning translation theories plays an important role in improving the level of translation.

First, functional equivalence theories. When translating, it is not required to have a rigid counterpart to the surface of the text, but it is necessary to achieve functional equivalence between two languages. It is not only the lexical equivalence, but also semantic, stylistic and type of writing. The information conveyed by the translation is not only the surface vocabulary, but also the deep cultural information. In literary translation, it is necessary to achieve equivalence from four aspects: vocabulary, grammar, literary piece, text and accurately reproduce the cultural connotation of the original text in the target language.

Second, polynary system theories. A polynary system is a hierarchy of layers consisting of a number of interrelated factors. Polynary system theories breakthrough with a single text, static and isolated to measure the success or failure of the translation limitations, which put translation studies in the larger cultural environment dynamic and system research, update the understanding of translation studies, expand contemporary translation studies' horizons, what's more, they have the pioneering significance for translation studies.

Third, the theory of faithfulness, expressiveness and elegance". It was brought forward by Yan $\mathrm{Fu}$, a Chinese enlightenment thinker, which opened the stage for the in-depth discussion of modem translation theories. "Faithfulness" is the basis of translation which expresses the "integrity" relationship between the original and the translation. "Expressiveness" is the purpose of translation which uses accurate words to express thoughts in the original text as possible. "Elegance" is the clothing of translation which digs out the artistic conception of the original text in furthest, also the reflect of the translation art.

\section{Existing Problems on English Translation for Chinese Cultural Classics}

Chinese cultural classics translation career has a considerable number of translation and research topics, which has made remarkable achievements, but also faces many problems, summarized as the following several aspects[1-6]:

First, the planning ability is not strong. Countries' civilizations of the world have their own characteristics, there are also great differences in cognition, reading, understanding and thinking patterns. In the process of Chinese cultural classics English translation, the subjectivity of selecting subjects is stronger, ignoring the recipient's habits, characteristics and abilities, which leads to that the discourse system and expression way of external publicity are too official that lack of charisma. For example, in the literature, attention are only paid to poems and novels, less translation on poetries of the Tang Dynasty and long narrative poems; and there is not enough attention in areas such as drama, calligraphy and painting.

Second, the disconnection between the theory and practice. The separation of theory and practice is still a serious phenomenon in the Chinese classical English translation. Most of people involved 
in the Chinese literary English translation practice are not engaged in the theoretical research. Those who work in theoretical research, who do not engage in translation practice, mainly introduce western translation theories to China. Also a number of master's and doctoral students with the translation major have no translation practice, just copy a western theory to review the existing translations. How to combine the theory with the practice and use the theory to guide practice to enrich and improve the theory in practice, which is an urgent problem to be solved in the Chinese classical English translation.

Third, ethnic minorities' classics are not taken seriously. Ethnic minority classics translation is an important part of Chinese cultural classics translation, existing main problems include: first, the number of ethnic minorities' classics English translation work is relatively small. The content of ethnic minorities' classics is rich and the number is large in our country, through efforts of the state and each session of the society, a large number of ethnic minority literature is found out, but the number of English translation is very rare. Second, theoretical research is slow. Personnel engaged in the work of ethnic minority classics translation is very scarce, the corresponding number of researchers is very small, which causes the slow development of ethnic minority classics English translation theory researches. Third, there is a serious shortage of funds. From the point of social science, it is very difficult for higher institutions to apply enough research grants, and the research funding of ethnic minorities classics English translation in the edge is more difficult to guarantee.

Fourth, cooperation and exchanges need to be strengthened. The Chinese classics English translation team is composed of two parts: foreign translators and Chinese translators. At present, existing problems are that the translation of overseas translators is mainly published overseas, the translation of domestic translation is mainly distributed in China, which lacks communication with each other. There are also lack of communication, cooperation and communication between scholars at domestic and abroad, and a lack of a comprehensive understanding of each other's studies in classics English translation. In addition, the people who are engaged in Chinese classics English translation practice are most, the people only engaged in classical literary translation, whose research methods are single and research field is narrow, which results in a low level and small range of repetitive work.

\section{Strategies on English Translation for Chinese Cultural Classics}

There are many practical problems in English translation of Chinese cultural classics, which need to be systematically studied comprehensively and multi-perspectively. This article takes the translation theory as the guide, based on the results of previous studies [7-10], Chinese cultural classics English translation strategies are put forward as follows:

First, integrating the academic research achievements of China and the west, taking the theory and practice of translation into account. Practice is the foundation of theory, which has a decisive effect on theory. Theory has a negative effect on the practice, the scientific theory has a positive guiding effect on practice, the wrong theory has the hindrance. Theory and practice complement each other, which are indispensable, separated from the dialectical relation of the two and emphasize one aspect in isolation. On the one hand, continuously carry out the translation practice, pay attention to researching and summarizing predecessors' translation experience, flexibly mastering methods and techniques of classics English translation, understanding theory in practice, putting forward own translation theory. On the other hand, the development of contemporary translation theory is very fast with more schools. The translator should consciously learn the modern translation theory, accept the norms and guidance of the theory, get inspiration from the theory, who improves the ability of translation research and practice.

Second, strengthen ethnic minority classics translation to promote the Chinese culture to go to the world. The rich and colorful ethnic minority culture is not only the precious cultural wealth of China, but also the world's precious wealth. It is the social responsibility that translators need to take on to translate many excellent ethnic minority classics into English. Specific strategies include: improving the consciousness of the mind, recognizing the importance of ethnic minority classics English translation; rational exploitation of resources which ensures the healthy development of 
minority nationality classics English translation; make a unified plan for the selection of minority nationality classics; strengthen the training of minority nationality classics English translation teams; deepen the theoretical research of minority nationality English translation; increase the application and approval of minority nationality classics English translation projects. The minority nationality classics translation with a fusion of various fields of ethnology, philology, history, literature, linguistics and translation has unlimited potential for development, it is necessary to seize the opportunity and make rational use of resources to create a situation of minority nationality classics English translation, which makes the minority nationality culture to the world.

Third, using the principle of cultural equivalence faces the existence of cultural differences. Cultural differences refer to the differences and similarities between people in different regions because of the similarities and differences of different regions. The difference between different cultures is due to the historical background and different aesthetic psychology, which is established in the social development and historical precipitation, a kind of permanent cultural phenomenon. Translation is the process that converting one language into another, the transfer of two languages must involve two cultures. In the field of translation, cultural equivalence is an effective way to solve cultural differences. To achieve cultural equivalence, it is necessary to constantly compare the two kinds of culture in the process of looking for "equivalents" considered with the original text, because the real equivalent value is reflected in their cultural meaning, function, scope, emotional color and effect. At the same time, something also should be realized that cultural equivalence is not absolute, and many situations can only be either dynamic or functional equivalence. In order to transmit the cultural connotation of the original language as far as possible, it is necessary to make use of explanations and annotations to make up for the cultural losses caused by means of literal translation and transliteration.

Fourth, strengthen the organization work of classics translation and explore multi unity and cooperation. The translation subject of Chinese cultural classics has experienced several development stages, such as foreigners, overseas Chinese and Chinese translators. In different development stages, the translation work shows a certain degree of gravity transfer. But there is still a lack of systematic and operational orderliness. Therefore, it must be done that strengthen the organization and leadership work of classics translation, systematic planning and implementation, organize large-scale translation and research projects at the national level, play a positive role of the state functionaries, publication editing departments and translation research departments. At the same time, play the positive role of academic research communities and social groups, especially the positive leading role of minority translation elites. In addition, the Chinese and foreign cooperation is also very important, in further attracting foreign scholars to participate in Chinese cultural classics translation work and trying the cooperation between domestic scholars and foreign scholars, which are not only limited to the European and American countries, give full consideration to scholars of other countries and regions whose interest in Chinese culture.

Fifth, constructing the classics translation corpus system solves pragmatic failure problems in help. The corpus refers to that large-scale electronic text library by scientific sampling and processing, which is the basis resource of corpus linguistics research, also the main resource of empirical language research methods. The translation corpus research has developed rapidly in recent years, many translation corporas, parallel corporas and comparable corporas have been built and put into use to create conditions for building the classics translation corpus system. The translation process can be roughly divided into three stages: understanding, expression and verification. In the understanding stage, translation corpus can help translators to determine the original semantics rhyme, the author semantics rhyme and the original style to improve the correctness of the understanding, which provides the premise and guarantee for the fidelity of the translation; in the expressing stage, through the synonyms, homoionym, words collocation and sentence pattern comparison of the corpus retrieval platform, a lot of reference words, sentences and expressions can be obtain to make the translation output more accurate; during the checking stage, the translation evaluation system is used to make quantitative analysis on the translation and find out the lack of the translation to embellish and perfect through data comparison. 
Sixth, strengthen the disciplines construction and cultivate excellent translation talents teams. The disciplines construction is the core of the construction and development of colleges, which is a long-term and arduous task of colleges. The level of the disciplines construction reflects the overall educational strength, academic status and core competence of institutions of higher learning, which is an important guarantee for improving the quality of talents. Translation as a subject, which is compared with the foreign language teaching, the translation education, the system construction and subject development of the translation subject are only just beginning. The disciplines construction must be strengthened through strengthening the leadership, making plans, introducing people, carrying out training, paying attention to scientific research, increasing investment and supervision. Emancipate the mind, establish the international idea, take the translation work and translation talents training as a long-term, systematic and strategic work, make scientific and reasonable planning and layout from the national level. Through planning national translation projects, agglomerating translation talents and focusing more resources, which makes excellent translation talents get more training opportunities.

\section{Conclusion}

Chinese cultural classics are the crystallization of ancient Chinese civilization and an important part of world civilization. However, due to language barriers and ideological differences, for a long time, little is known about the ancient culture of China in the west, translating Chinese cultural classics into English is a basic work, which needs a lot of people unremitting efforts to carry out a long period of cultural accumulation. The translation of cultural classics is a complicated system project which requires careful planning and implementation, and the participation of various forces. As a major intercultural activity, it needs the party and government to give more support and guidance, it is necessary for translation circles, the academia and press to unite and work together to translate literary works, which makes the Chinese culture go to the world and promotes the development of human civilization and peace.

\section{References}

[1] S. F. Huang, "Reflections on the translation of Chinese classics from the perspective of discourse power," China Publishing Journal, vol. 38, no. 7, pp. 61-63, 2015.

[2] X. Q. Gu, "English translation of Chinese classics: achievements, problems and countermeasures," Overseas English, vol. 16, no. 5, pp. 155-156, 2015.

[3] T. Xue, The dilemma and breaking of English translation of Chinese ethnic minorities," Guizhou Ethnic Studies, vol. 36, no. 10, pp. 131-134, 2015.

[4] C. Y. Wang, "Status quo and Prospect of English Translation of Chinese Minorities Classics," Journal of Yulin Normal University, vol. 35, no. 1, pp. 80-83, 2014.

[5] H. Y. Wang, "Problems of Translating Chinese Classics and Solutions," Chinese Culture Research, vol. 23, no. 2, pp. 59-68, 2015.

[6] H. Wang, "English translation of Chinese classics: Achievements, problems and solutions," Foreign Language Learning Theory and Practice, vol. 32, no. 3, pp. 9-14, 2012.

[7] Z. X. Huang, "English translation of Chinese Classics: opportunities and challenges," Social Sciences in Ningxia, vol. 27, no. 6, pp. 177-179, 2008.

[8] L. D. Fan, "On the Problem of Classics Translation Practice," Journal of Jiaozuo University, vol. 26, no. 4, pp. 51-52, 2012.

[9] L. Y. Liu, "Foreignization, Domestication and Cultural Equivalence in Translation," Journal of Chongqing University of Arts and Sciences (Social Sciences Edition), vol. 5, no. 1, pp. 61-64, 2006.

[10] H. Zhang, "Translation and dissemination of Chinese cultural classics," Journal of Shenyang Normal University (Social Science Edition), vol. 37, no. 4, pp. 186-189, 2013. 